\title{
Accuracy of Fine Needle Aspiration Cytology in Solitary or Dominant Nodular Goitre: A Single Centre Study
}

\author{
${ }^{a} M$. Rohaizak, ${ }^{b} Y$ Aman Fuad, ${ }^{c}$ I Naqiyah, a J.J Saladina, ' $A . S$ Shahrun Niza \\ ${ }^{a}$ Endocrine and Breast Unit, Department of Surgery, Universiti Kebangsaan Malaysia Medical Centre (UKMMC), \\ Jalan Yaakub Latif, Bandar Tun Razak, 56000 Kuala Lumpur \\ ${ }^{b}$ Kementerian Kesihatan Malaysia, Kompleks E, Pusat Pentadbiran Kerajaan Persekutuan, 62590 Putrajaya \\ 'KPJ Damansara Specialist Hospital, 119 Jalan SS 20/10, Damansara Utama, 47400 Petaling Jaya, Selangor
}

\begin{abstract}
Background: Thyroid swelling or goitre is a common condition, either asymptomatic or symptomatic. The diagnosis is usually established by ultrasound or fine needle aspiration cytology (FNAC) as a gold standard. The sensitivity of the test is inversely related to increasing size of the nodule. The objective of this study is to evaluate the accuracy of FNAC especially in cases of large goitre. Material and methods: This is a retrospective study on patients who underwent thyroidectomy between January 2000 to December 2007 for solitary or dominant nodular goitre. The analysis was made only on those patients with complete data on FNAC and histology. Result: There were 235 patients, but only 161 patients were analysed after excluding the suspicious and inadequate sample. The patients' mean age was 42.1 year old ( 21 to 60 ). The size of the thyroid nodule ranged from 2.1 to $5.0 \mathrm{~cm}$ (mean $=3.9 \mathrm{~cm}$ ). The overall sensitivity was $67.4 \%$ and the overall accuracy was $86.3 \%$. The accuracy of FNAC according to the sizes above and below the value were as follows; $2 \mathrm{~cm}(72.2 \%$ vs. $88.1 \%) ; 3 \mathrm{~cm}(88.0 \%$ vs. $87.4 \%) ; 4 \mathrm{~cm}(86.6 \%$ vs. $84.4 \%) ; 5 \mathrm{~cm}(87.3 \%$ vs. $78.8 \%)$. This was most obvious in the sensitivity of the FNA which also showed reducing trend as the nodules increased in size. Conclusion: FNAC is an essential diagnostic tool in the management of nodular goitre. Our study showed that the accuracy of FNAC decreased as the size of the nodule getting bigger. Cautious approach should be taken in the management of large goitre and decision should not be based only on the result of FNAC.
\end{abstract}

KEYWORDS: thyroid, goitre, cytology, biopsy, aspiration

\section{INTRODUCTION}

Fine needle aspiration cytology (FNAC) is an established procedure and frequently been used as the first line investigation for thyroid nodules or any lumps occurring anywhere in the body. The procedure is least invasive and has become the gold standard tool for the diagnosis of palpable lesions especially in the neck. Recently, a diagnostic ultrasound of the thyroid before biopsy has changed the management of thyroid diseases. Suspicious features on ultrasound will guide the operator to the area to be biopsied and this improved the accuracy of the biopsy. ${ }^{1}$ Unfortunately, it becomes very useful only when a positive result is obtained. In the presence of a negative result or benign condition, the predictive value decreases

Corresponding author:

Prof. Dr. Rohaizak Muhammad

Consultant Endocrine and Breast Surgeon,

Department of Surgery,

Universiti Kebangsaan Malaysia Medical Centre,

54200 Kuala Lumpur

Email: rohaizak@hotmail.com significantly. ${ }^{2-7}$ Study by Carillo et al showed that false negative of FNAC was clinically significant when the size of the thyroid nodule was more than $4 \mathrm{~cm}^{2}{ }^{2}$ Looking at the risk of malignancy in large goitre, Brucanardi et.al found a $15 \%$ incidence of malignancy, hence recommended thyroid lobectomy for cysts greater than $4 \mathrm{~cm}$ in diameter and complex cysts with solid and cystic components. ${ }^{6}$

Therefore, the objective of this study is to evaluate the sensitivity of FNAC in detecting malignancy in nodular thyroid goitre in patient who had undergone surgery at the Universiti Kebangsaan Malaysia Medical Centre (UKMMC) from year January 2000 to December 2007.

\section{METHODOLOGY}

This is a retrospective study on all patients with solitary or dominant thyroid nodule who underwent thyroid surgery at the Surgical Department, UKMMC from January 2000 to December 2007. Data were collected from the hospital computer system and analysis was performed only on patients with complete histopathology report (HPE) and fine needle aspiration cytology (FNAC), either standard free hand or ultrasound-guided. The procedure was performed by trainees in pathology and read by cytopathologist. When there was more than one 
biopsy taken, only the latest FNAC was taken for analysis. Other parameters collected were gender, age and histological size (diameter) of largest nodule. Size of nodule taken was the size reported on gross specimen for histopathological examination.

\section{RESULTS}

There were 403 patients who had a form of thyroid surgery in UKM Medical Centre from year 2000 until 2007 for various indications. Elghty patients (19.9\%) were diagnosed with thyroid cancer (Table 1). Only 235 (58.3\%) patients had FNAC prior to the operation and available for analysis. Majority (86\%) of the patients were female. Sixty five percents of the patient were between 41 to 50 years old. Malay ethnic patients formed the majority of the patients consisting of 151 patients $(64.3 \%)$, followed by Chinese 67 patients $(28.5 \%)$ and Indians 16 patients $(6.8 \%)$. The mean size of the tumour was $3.9 \mathrm{~cm}$ with $85 \%$ of patients having a solitary or dominant thyroid nodule larger than $2 \mathrm{~cm}$.

Two hundred and thirty five patients underwent FNA with 124 patients (52.8\%) having benign result.

Table 1. General clinical characteristic distribution of study population

\begin{tabular}{|c|c|c|c|}
\hline & Variables & $\begin{array}{c}\text { Total } \\
(\mathrm{N}=235)\end{array}$ & $\%$ \\
\hline \multirow[t]{2}{*}{ Gender } & Male & 33 & 14.04 \\
\hline & Female & 202 & 85.96 \\
\hline \multirow[t]{7}{*}{ Age (years) } & $\leq 20$ & 12 & 5.11 \\
\hline & $21-30$ & 41 & 17.45 \\
\hline & $31-40$ & 54 & 22.98 \\
\hline & $41-50$ & 65 & 27.66 \\
\hline & $51-60$ & 36 & 15.32 \\
\hline & $61-70$ & 23 & 9.79 \\
\hline & $\geq 71$ & 4 & 1.70 \\
\hline \multirow[t]{4}{*}{ Ethnicity } & Malay & 151 & 64.26 \\
\hline & Chinese & 67 & 28.51 \\
\hline & Indian & 16 & 6.81 \\
\hline & Others & 1 & 0.43 \\
\hline Size of & $\leq 1.0$ & 4 & 1.70 \\
\hline largest or & $1.1-2.0$ & 30 & 12.77 \\
\hline dominant & $2.1-3.0$ & 66 & 28.09 \\
\hline nodule & $3.1-4.0$ & 46 & 19.57 \\
\hline \multirow[t]{5}{*}{$(\mathrm{cm})$} & 4.1-5.0 & 46 & 19.57 \\
\hline & $5.1-6.0$ & 25 & 10.64 \\
\hline & 6.1-7.0 & 7 & 2.98 \\
\hline & $7.1-8.0$ & 7 & 2.98 \\
\hline & $\geq 8.1$ & 4 & 1.70 \\
\hline
\end{tabular}

Thirty seven patients (15.7\%) were reported as malignant, 60 patients $(25.5 \%)$ suspicious and 14 patients $(6.0 \%)$ had inadequate sampling. Table 2 showed the distributions of FNAC compared to the histopathology examination (HPE) report.

Amongst the patient with benign FNAC $(n=124)$, $11.3 \%(n=14)$ had malignant thyroid cancer on histology. Out of 37 patient who had malignant FNAC sampling, $21.6 \%(\mathrm{n}=8)$ had benign disease on their final histology.

Table 2: Distribution of FNAC and Histopathology Examination(HPE) result

\begin{tabular}{clccc}
\hline & & \multicolumn{2}{c}{ HPE } & Total \\
& & Benign & Malignant & \\
\hline FNAC & Benign & 110 & 14 & 124 \\
& & & & $(52.8 \%)$ \\
& Inadequate & 13 & 1 & 14 \\
& Suspicious & 46 & 14 & $(6.0 \%)$ \\
60 \\
& Malignant & 8 & 29 & $(25.5 \%)$ \\
37 \\
& & & & $(15.7 \%)$ \\
& Total & 177 & 58 & 235 \\
\hline
\end{tabular}

Table 3 shows the result of the analysis after the exclusion of suspicious and inadequate FNAC $(n=161)$. In this group of patients, $23 \%$ had malignant FNAC with $77 \%$ had benign FNAC. With this finding, the sensitivity of the FNAC was $67.44 \%$ with specificity of $93.2 \%$. False positive rate was $6.8 \%$, false negative of $32.6 \%$ and the accuracy of $86.3 \%$.

The analysis was further performed by grouping them according to the size of the nodule. The sensitivity, specificity, false-positive, false negative, accuracy, positive predictive value and negative predictive value were further calculated. Table 4 showed that the sensitivity of FNA reduced with increasing size of the thyroid nodule. Similarly, the negative predictive value also reduced dramatically with the increasing size of the thyroid nodule.

Table 3: FNAC compared to HPE and the predictive values $(\mathrm{n}=161)$

(Suspicious and inadequate FNAC were excluded)

\begin{tabular}{lcccc}
\hline & \multicolumn{3}{c}{ HPE } \\
& $\begin{array}{c}\text { Malignant } \\
\text { (positive) }\end{array}$ & $\begin{array}{c}\text { Benign } \\
\text { (negative) }\end{array}$ & Total \\
\hline \multirow{2}{*}{ FNAC } & $\begin{array}{c}\text { Malignant } \\
\text { (positive) } \\
\text { Benign }\end{array}$ & 29 & 8 & 37 \\
& $\begin{array}{c}\text { (negative) } \\
\text { Total }\end{array}$ & 14 & 110 & 124 \\
\hline
\end{tabular}

Sensitivity, $29 / 43$ (67.44\%); specificity, 110/118 (93.22\%; false-positive, 8/118(6.78\%); false-negative, 14/43 (32.56\%); and accuracy 139/161 (86.34\%). 
Table 4: Sensitivity, Specificity and Predictive Value of FNAC at different nodule size

\begin{tabular}{|c|c|c|c|c|c|c|c|c|c|}
\hline \multirow{2}{*}{$\begin{array}{l}\text { Size } \\
(\mathrm{cm})\end{array}$} & \multicolumn{2}{|c|}{$\begin{array}{c}\text { FNAC } \\
\text { benign } \\
(\mathrm{N}=124)\end{array}$} & \multicolumn{2}{|c|}{$\begin{array}{c}\text { FNAC } \\
\text { Malignant } \\
(\mathrm{n}=37)\end{array}$} & \multirow[b]{2}{*}{ Sensitivity } & \multirow[b]{2}{*}{ Specificity } & \multirow[b]{2}{*}{$\begin{array}{l}\text { Negative } \\
\text { predictive } \\
\text { value }\end{array}$} & \multirow[b]{2}{*}{$\begin{array}{l}\text { Positive } \\
\text { predictive } \\
\text { value }\end{array}$} & \multirow[b]{2}{*}{ Accuracy } \\
\hline & $\begin{array}{l}\text { HPE } \\
\text { benign } \\
n=110\end{array}$ & $\begin{array}{c}\mathrm{HPE} \\
\text { malignant } \\
\mathrm{n}=14\end{array}$ & $\begin{array}{c}\mathrm{HPE} \\
\text { malignant } \\
\mathrm{n}=29\end{array}$ & $\begin{array}{c}\mathrm{HPE} \\
\text { benign } \\
\mathrm{n}=8\end{array}$ & & & & & \\
\hline$<2$ & 7 & 2 & 6 & 3 & 0.75 & 0.70 & 0.78 & 0.67 & 0.72 \\
\hline$\geq 2$ & 103 & 12 & 23 & 5 & 0.66 & 0.72 & 0.90 & 0.82 & 0.82 \\
\hline$<3$ & 31 & 3 & 11 & 5 & 0.78 & 0.86 & 0.91 & 0.69 & 0.88 \\
\hline$\geq 3$ & 79 & 11 & 18 & 3 & 0.62 & 0.96 & 0.88 & 0.86 & 0.87 \\
\hline $\begin{array}{l}<4 \\
\geq 4\end{array}$ & $\begin{array}{l}56 \\
54\end{array}$ & $\begin{array}{c}4 \\
10\end{array}$ & $\begin{array}{l}15 \\
14\end{array}$ & $\begin{array}{l}7 \\
1\end{array}$ & $\begin{array}{l}0.79 \\
0.58\end{array}$ & $\begin{array}{l}0.89 \\
0.98\end{array}$ & $\begin{array}{l}0.93 \\
0.84\end{array}$ & $\begin{array}{l}0.68 \\
0.93\end{array}$ & $\begin{array}{l}0.87 \\
0.86\end{array}$ \\
\hline$<5$ & 84 & 7 & 19 & 8 & 0.73 & 0.91 & 0.92 & 0.70 & 0.87 \\
\hline$\geq 5$ & 26 & 7 & 10 & 0 & 0.59 & 1.00 & 0.78 & 1.0 & 0.84 \\
\hline
\end{tabular}

\section{DISCUSSION}

Thyroid malignancy is not an uncommon condition but thyroid nodules are a common finding on the ultrasound of the neck. Clinical factors that point towards malignancy include older age (more than 50 ), hard nodule and size of the nodule more than 4 $\mathrm{cm}^{2,8}$ Fine needle aspiration cytology is the most essential part of the diagnostic investigation for the thyroid nodule. The sensitivity and specificity of the test been reported to be as high as $95 \%^{2-9}$ but are affected by several factors including size of the thyroid nodule and operator learning curve in performing the procedure and interpreting the result. ${ }^{10}$

Carillo et al published an article in year 2000 looking the accuracy of FNAC of thyroid nodule in combination with clinical and radiological evaluation. There were 159 patients who had FNAC and underwent thyroid surgery for various reasons. The clinical parameters analysed were age of patient, lesion mobility, quality of borders, consistency of the nodule, type of growth and ultrasound echogenicity. The study concluded that the only associated false negative result was thyroid nodule size more than $4 \mathrm{~cm}^{2}$

Stang and Carty published in 2008 and concluded that FNAC was the most accurate predictor of thyroid nodule malignancy with false negative rate between $1-11 \%$, and varied widely due to diagnostic category. ${ }^{8}$ They also found that the significant cause of FNAC sampling error which leads to false positive was due to large thyroid nodule. Based on this study, they proposed that thyroid nodule bigger than $4 \mathrm{~cm}$ should undergo lobectomy regardless of the FNAC result. In their series of patient with more than $4 \mathrm{~cm}$ nodules, their false negative rate of FNAC was $12.7 \%$ with cancer detection rate at $19.3 \%$. They also found that that FNAC of follicular neoplasm category had histological malignancy of $33 \%$.
In our study, there was a high false negative rate for thyroid nodule more than $4 \mathrm{~cm}(41.7 \%)$. For nodules bigger than $3 \mathrm{~cm}$, the false negative rate of FNAC was still high at $37.9 \%$. While for nodule less than 3 $\mathrm{cm}$ and $4 \mathrm{~cm}$, the false negative rate were $21.4 \%$ and $21.1 \%$ respectively, which was nearly similar. Looking at the nodules bigger than $5 \mathrm{~cm}$, the false negative rate markedly increased to $46.7 \%$, with drop in accuracy to only $83 \%$. These result suggested that the larger thyroid nodules were associated with more false negative FNAC. This is consistent with other reports which suggested similar findings.

The problem with studies comparing FNAC to HPE report is that only a few benign thyroid nodules less than $3 \mathrm{~cm}$ or $4 \mathrm{~cm}$ had been operated. ${ }^{11-15}$ Our data showed that the sensitivity tests for small thyroid nodules of size less than $3 \mathrm{~cm}$ and $2 \mathrm{~cm}$ were good at $78 \%$ and $75 \%$ respectively. But the result may not be accurate as many patients with small benign nodules were not operated to be included in the study. Data on free hand and ultrasound guided were analysed together as the sample size is small which might also affect the result as the accuracy of the two techniques might be different. What is evident from this study, the accuracy of FNA decreases with enlarging size of the nodule, which might be due to a large nodule harbouring small area of malignancy.

\section{CONCLUSIONS AND RECOMMENDATION}

The sensitivity of FNA decreases with increasing size of the nodule. Therefore, the current recommendation to remove nodule bigger than $4 \mathrm{~cm}$ is justified. But this should not prevent clinicians to proceed with FNAC for large thyroid as positive result will still be useful in the management of the patient. Targeted FNAC using ultrasound guidance on lesions with sonographic evidence of malignancy should be explored for better and precise cytology. 


\section{REFERENCES}

1. Brito JP, Gionfriddo MR, Al NA, Boehmer KR, Leppin AL, Reading C, Callstrom M, Elraiyah TA, Prokop LJ, Stan MN, Murad MH, Morris JC, Montori VM The accuracy of thyroid nodule ultrasound to predict thyroid cancer: systematic review and meta-analysis. J Clin Endocrinol Metab 2014;99:1253-63

2. Carrillo JF, Frias-Mendivil M, Ochoa-Carillo FJ, Ibarra M. Accuracy of fine-needle aspiration biopsy of the thyroid combined with an evaluation of clinical and radiologic factors. Otolaryngol Head Neck Surg 2000;122:917-21.

3. Neki NS, Kazal HS, Solitary thyroid nodule - An insight. Journal Indian Academy of Clinical Medicine 2006;7:328-33.

4. Ogilvie JB, Pitigorsky EJ, Clark OH. Current Status of Fine Needle Aspiration for Thyroid Nodules. Adv Surg 2006;40:223-38.

5. Kuru B. Triaging Patients with Thyroid Nodules for Surgery by Fine Needle Aspiration Cytology. Am J Surg 2008;195:881-2

6. Brunicardi CF, Anderson DK, Billiar TR, Dunn DL, Hunter JG, Pollock RE, Schwartz's Principle of Surgery ${ }^{8 \text { th }}$ Ed, 2004; Chapter 37.

7. Mahar SA. Husain A, Islam N. Fine Needle Aspiration Cytology of Thyroid Nodule: Diagnostic Accuracy and Pitfalls. Journal of Ayub Medical College 2006;18:26-9.

8. Stang MT, Carty SE, Recent developments in predicting thyroid malignancy. Curr Opin Oncol 2008;21:11-7.

9. Carpi A, Mechanick JI, Nicolini A, Rubello D, lervasi G, Bonazzi V, Giardino R. Thyroid Nodule Evaluation: What Have We Really Learned from Recent Clinical Guidelines? Biomed Pharmacother 2006;60:393-5.

10. Arda IS, Yildrim S, Demirhan B, Firat S. Fine Needle Aspiration Biopsy of Thyroid Nodules. Arch Dis Child 2001;85:313-7.

11. Meko JB, Norton JA, Large cystic/solid thyroid nodules: a potential false negative fine-needle aspiration. Surgery 1995;1:996-1003.

12. Delbrige L, Solitary Thyroid Nodule: Current Management. ANZ Journal Surgery 2006; 76:3816.

13. Bater MC, Mackenzie N, Webb RA, Brennan PA. Fine needle aspiration cytology - Does needle size matter? Br J Oral Maxillofac Surg 2007;45:e30-e63.

14. Sakorafas GH, Peros G, Farley DR. Thyroid Nodules: Does the Suspicion for Malignancy Really Justify the Increased Thyroidectomy Rates? Surg Oncol 2006;15:43-55.

15. Morgan JL, Serpell JW, Cheng MSP, Fine-Needle Aspiration Cytology of Thyroid Nodules: How Useful Is It? ANZ J Surg 2003;73:480-3. 